\title{
JEJE: REPENSANDO NAÇÕES E TRANSNACIONALISMO
}

\author{
J. Lorand Matory
}

Este ensaio é uma tentativa de reteorizar a diáspora africana a partir de duas produções recentes e altamente provocativas. A primeira é o corpo de escritos que se segue à publicação do livro I magined Communities, de Benedict Anderson (1991[1983]), e a segunda trata das noções de "transnacionalismo" e "globalização" articuladas por Appadurai (1990), Gupta, Clifford (1997), Hannerz (1996), Glick Schiller, Basch, Blanc-Szanton (1992) e outros. M eu objeto de investigação exige, pois, reconsiderar os conceitos de "nação" e "transnacionalismo".

Benedict Anderson argumenta em seu livro que a definição territorial de nação é nova e que a comunidade baseada em seu território é menos objetiva que imaginada - imaginada por uma imprensa vernacular e monolingüística, e pela leitura a partir da qual é construída uma experiência compartilhada, apesar das grandes distâncias geográficas e sociais que separam os diversos cidadãos.

Por outro lado, temos visto recentemente centenas de escritos sobre o nascimento recente de comunidades culturais, econômicas, políticas e sociais que transcendem, transbordam e atravessam as fronteiras de múltiplas nações. Os defensores desta idéia tendem a identificar o começo do fenômeno com alguma transformação relativamente recente, como, por exemplo, a revolução marítima européia há quinhentos anos. Ou, mais freqüentemente, com a implosão dos impérios coloniais europeus a partir da Segunda Guerra M undial, ou, ainda mais freqüentemente (pelo menos na literatura norte-americana), com a revisão das leis de imigração norte-americanas e com as melhorias técnicas de transporte e comunicação desde os anos 60.

Assim, o primeiro alvo deste ensaio é questionar essa suposição de excepcionalidade pós-colonial e lembrar que várias formas de dispersão eram precondições, ou parceiros contemporâneos, do desenvolvimento da nação territorial de Anderson. O segundo é estender as referências 
dessas revisões teóricas. A maior parte do discurso sobre nacionalismo hoje em dia trata do movimento de pessoas e idéias do Norte para o Sul (isto é, basicamente desde a Europa e as A méricas brancas para o resto do mundo). Por outro lado, a maior parte dos discursos sobre o transnacionalismo trata do movimento de capitais para o Sul ou, mais freqüentemente, do movimento de trabal hadores para o N orte. O caso que discutirei aqui é o de um movimento de pessoas e idéias do Sul para o Sul, em um contexto de diálogo com o N orte no seu domínio militar. Nesse diálogo, a agency do Sul - e mesmo, digamos, do extremo Sul (isto é, dos africanos raptados) - evidencia-se claramente.

Do século XV ao XIX, segundo estimativas modestas, pelo menos 10 milhões de africanos foram embarcadas à força para as A méricas (ver, $p$. ex., Curtin 1969). Esta foi a maior imigração transoceânica na história da humanidade até aquela época. Foi com certeza mais ampla do que a imigração dos europeus para as A méricas ocorrida no mesmo período. Ainda hoje, muitos descendentes daqueles africanos raptados se reconhecem como integrantes de "nações" diaspóricas, para usar um termo que é especialmente comum na América Latina, mas que também não é raro na América do Norte (considere-se, por exemplo, que os negros norteamericanos têm um hino nacional ${ }^{1}$ ). Há também as naciones arará, congo e lucumí em Cuba (ver, p. ex., Ortiz 1973[1906]; Cabrera 1983[1954]; Brandon 1993:55-59), assim como as nações jeje, congo-angola e nagô no Brasil (Encontro de Nações-de-Candomblé 1984; Bastide 1978[1960]; Costa Lima 1976). De modo um pouco diferente, verifica-se a existência das nachons rada, congo e nago no Haiti (M étraux 1972[1959]).

Segundo o modelo convencional de Nina Rodrigues, Arthur Ramos, M elville J. Herskovits e, em Cuba, de Fernando Ortiz, essas nações eram grupos étnicos africanos que foram levados para o Novo M undo e, até certo ponto, lá "sobreviveram". De fato, essas nações eram freqüentemente agrupamentos impostos a diversos povos e a distintas ordens de categorias políticas, lingüísticas e culturais que foram unificados primariamente para os propósitos dos traficantes de escravos. Desse modo, com o apoio de Roger Bastide e outros, o musicólogo Gerhard Kubik chama essas nações, ou categorias étnicas, de "trademarks", ou "marcas registradas" (Kubik 1979).

Isto não quer dizer que esses agrupamentos não possuíssem afinidades culturais ou potencialmente políticas. Suas afinidades reais, imaginadas ou potenciais estavam entre as razões que fizeram com que acabassem sendo reunidos de modo similar no Haiti, em Cuba e no Brasil para não falar no restante da A mérica Latina. O que quero enfatizar é 
que um grande trabalho cultural e institucional foi necessário para amalgamá-los em "nações". Uma parte desse trabalho foi feita pelos donos de escravos e pela Igreja Católica. Alguns grupos étnicos foram preferidos em detrimento de outros em certas áreas da produção; os projetos de evangel ização realizados pela Igreja Católica geraram irmandades que afirmaram essas identidades emergentes e integraram modos ancestrais de celebrar e adorar o divino. Cantos, ou turmas de trabal hadores, também se juntaram na base dessas identidades. $E$, como muitos sabem, tanto conspirações e rebeliões quanto anticonspirações, freqüentemente, seguiam e afirmavam essas novas divisões sociais (ver, p. ex., Holloway 1990; Wood 1975:35; Bastide 1978:47; Russell-Wood 1974:579; Verger 1987:525; 1976:285-313, 426, 465; Mattoso 1986[1979]:129; Reis 1987).

Essas nações ainda vivem de acordo com as denominações dos vários templos das religiões afro-cubana e afro-brasileira, como o Candomblé, e dos vários deuses e ritmos de tambor sagrados em Cuba, no Brasil e no Haiti. A história parece simples quando imaginamos essas nações no final do século XIX, e hoje em dia, como sendo nada mais do que memórias esmaecidas do passado, como "folclore" de certo modo diferente e desligado da realidade única da nação territorial. Costa Lima, por exemplo, argumenta que essas nações eram originalmente "nações políticas africanas", mas foram "aos poucos perdendo sua conotação política para se transformar num conceito quase exclusivamente teológico [e ritual]" (1977:77-78, 21). Ao contrário, a história parece-nos muito mais interessante quando verificamos que essas nações eram identificadas como indígenas na África, como unidades territoriais, políticas ou lingüísticas até período bem recente, quando um grupo pequeno, mas influente, de afro-brasileiros, afro-cubanos, negros norte-americanos e serraleoninos "voltaram para casa", para o Golfo da Guiné. A verdade é que essa afirmação fica um tanto imprecisa, visto que muitos deles não nasceram no Golfo da Guiné, e tampouco na África, nem todos tiveram ancestrais nos lugares africanos para onde "regressaram". Os chamados "retornados" tiveram de imaginar, por meio de uma construção seletiva e criativa, a história de onde e do que era sua "casa", ou "lar". Argumento que a imaginação a respeito dos limites das nações dispersas e da casa gerou muitas vezes novas identidades étnicas e nacionais na África. Como veremos adiante, essa nacionalidade transoceânica subsiste, nem mais nem menos do que a nação territorial, nas formas de imaginação que formaram ambos os tipos de nação durante os dois séculos anteriores.

A história do termo "nação" não começou com o tráfico de escravos nem sequer com a formação da nação territorial, que, segundo Benedict 
Anderson (1991[1983]), ocorreu no final do século XVIII. Desde muitos séculos, "nação" e seus cognatos nas línguas européias têm o sentido de um grupo de pessoas ligadas nitidamente pela ascendência, língua ou história compartilhadas a ponto de formarem um povo distinto. $O$ que nos interessa especificamente neste artigo é a emergência em paralelo de dois usos rivais do termo, os dois coincidindo com a colonização européia das A méricas. Modificando a tese de Anderson, argumento que a nação territorial nas A méricas emergiu não de um diálogo isolado com a Europa, mas também de um diálogo com as nações transatlânticas e supraterritoriais geradas pela colonização africana desses continentes. $E$, ao contrário da tese de A ppadurai (1996), tais unidades supraterritoriais prefiguram não o fim, mas o começo da nação territorial. De fato, o diálogo com a nação diaspórica forma a base da nação territorial americana, africana e européia.

\section{Das origens transatlânticas dos "Yorùbá"}

Esta revisão histórica começa com um caso que discuti extensamente em outros textos (M atory no prelo; 1998; 1999). Ele é relevante aqui não apenas porque reavalia a história do mais famoso dentre os povos da África Ocidental, mas porque este povo é vizinho daquele de que este ensaio trata principalmente. Esses dois povos ocupavam lados opostos da fronteira colonial britânica/francesa, cujo poder simbólico perdurou ao longo da diáspora africana, resultado da comunicação contínua entre Europa, África e as Américas durante a época de imperialismo britânico e francês.

Um aspecto muito importante do livro que acabo de escrever trata especificamente do vai-e-vem de pessoas, de textos e de idéias entre Lagos, Serra Leoa, Cuba e Brasil. Afirmo, tendo como base o argumento de Law (1977), que, antes de o tráfico de escravos no século XIX dispersar os Ijèbú, os Egbá, os Egbádò, os Ondó, os Ekiti, os Oyó e outros, estes grupos nunca se autodenominaram "Yorùbá", muito menos compartilharam uma língua "padrão" ou uma identidade política única. Argumento que foi a dispersão e as atividades de milhares de retornados durante a fase de colonialismo britânico que produziu a identidade novamente unitária chamada "Yorùbá". Ademais, formas de escrever e de literatura inspiradas pelos ingleses e a reação auto-afirmativa dos retornados ao racismo britânico fizeram dos "Yorùbá" a "nação" africana mais prestigiosa no perímetro Atlântico². Esse prestígio conformou as vidas social, política 
e religiosa não só no interior de Lagos, mas também no Brasil, em Cuba, em M iami e em Nova Iorque. Em suma, nesse livro trato da mediação colonial e pós-colonial da identidade étnica.

O presente artigo também trata da mediação colonial e pós-colonial da identidade étnica e nacional. O motivo explícito é reavaliar supostos padrões de que, primeiro, os grupos étnicos africanos como tal existiram a partir do começo da raça humana (e, daí, pouco mudaram) e, segundo, esses grupos antediluvianos são as "origens" das culturas afro-americanas. Também, implicitamente, este trabalho sugere a reavaliação da lógica "de-cima-para-baixo" da escola da "invenção da tradição", representada pelas numerosas publicações a partir de 1983 que citam o livro A Invenção da Tradição, editado por Eric Hobsbawm e Terence Ranger (1992). O tema central dos artigos ali contidos, como o da recente etnografia do Candomblé e do Xangô (p. ex., Dantas 1988; Henfrey 1981; M otta 1994), é que muitas das tradições mais veneradas que legitimaram o Estado e as classes governantes foram inventadas, confeccionadas, a partir de um tecido de mentiras para servir aos interesses das classes governantes. O que não está presente nesta formulação é, primeiro, as condições de plausibilidade cultural de qualquer "tradição inventada" e, segundo, os interesses, o consentimento e a contribuição das outras classes que produzem a "tradição". O que me parece evidente no caso da identidade yorùbá é a agency - ou intencionalidade e ação estratégica bem-sucedida - dos oprimidos e sua sabedoria cosmopolita. Os viajantes afro-brasileiros conseguiram investir poder em suas novas formas de solidariedade transregionais e transoceânicas.

\section{A nação "voodoo"}

Outro grupo de identidades ficou famoso nos Estados Unidos, ironicamente, pelos filmes Voodoo - filmes de horror inspirados no profundo racismo e etnocentrismo pelo encontro do exército norte-americano com o povo haitiano durante a ocupação desse país entre 1915 e 1933.

$O$ termo voodoo em inglês vem da palavra vodun, que significa "divindade" ou "deus" no grupo dialetal ewe-gen-aja-fon do Golfo da Guiné - a oeste da localização contemporânea dos yorùbá. Há muitos séculos, saíram várias dinastias da cidade de Tado, atualmente no Togo. Tais dinastias fundaram os reinos de Allada, Daomé e Hogbonou ou Porto-Novo. Elas e seus súditos acabaram por falar diversos dialetos (ver, $\mathrm{p}$. ex., Akindélé e Aguessy 1953; Pliya 1970; Capo 1984). 
O lingüista Hounkpati Capo explica assim a variação dialetal:

“[...] há uma inteligibilidade mútua entre dialetos que são contíguos, por exemplo, ewe, gen e aja, aja e fon e assim por diante; mas o grau de inteligibilidade mútua corresponde à distância 'geográfica', p. ex., embora haja alguma inteligibilidade mútua entre ewe e aja, é menor que aquela entre ewe e gen, e não parece haver nenhuma inteligibilidade mútua entre ewe e fon[,] os quais são os pólos extremos do grupo dialetal (Capo 1984:168).

Ademais, como súditos de diversos reinos, esses grupos não pertenciam a nenhum grupo politicamente unido. De fato, achavam-se muitas vezes em guerra uns contra os outros.

Durante o século XVII e começo do XVIII, o reino de Allada dominava o comércio com os europeus nessa região. A oeste achava-se o famosíssimo Castelo de São J orge da Mina, o qual desempenhou um papel importante no comércio afro-europeu. Nesse período, traficantes de escravos e viajantes europeus identificaram vários povos adoradores dos voduns e chamaram-nos coletivamente de "Ardra/Arder/Ardres" (do nome do reino de "Allada") e "Minas" (do nome do Castelo de São J orge da Mina). Em seguida, encontramos populações no Haiti chamadas de "Rada" e em Cuba de "Arara". No Brasil e na Louisiana francesa foram denominadas "M inas". No entanto, em um certo momento, em meados do século XVIII, no Brasil, esses mesmos povos adoradores dos voduns passaram a ser conhecidos como "J ejes". Este nome é para mim um mistério. Embora os falantes de ewe, gen, aja e fon tivessem sido embarcados em maior número antes de 1800, não encontrei nenhuma menção a esse nome no Golfo da Guiné até 1864, depois do fim efetivo do tráfico de escravos3.

O termo “jeje” aparece nos documentos brasileiros a partir de 1739, embora esteja ausente da cartilha escrita no Brasil por Peixoto (194344[1741]), que parece tratar da mesma língua (sobre menções aos “jeje” no século XVIII, ver Verger 1976:6, 7, 17, 381, 450, 462, 593 e ss.; Rodrigues 1945[1905]:176; Reis 1983)4. A adoração dos deuses vodun deixa pouca dúvida de que a sua religião veio da zona entre o Castelo de São J orge da Mina e a região agora chamada de "Terra dos Yorùbá" : é nessa área que os deuses são chamados de vodun. Porém, para brasileiros e brasilianistas, a origem do nome peculiar “jeje” fica como dúvida. Inspirado pelo título de Ellis (The Ewe-Speaking Peoples of the Slave Coast of West A frica, 1970[1890]), Rodrigues estabeleceu a tradição etimológica brasileira de identificar a palavra "ewe" — o nome do dialeto falado ago- 
ra no sudoeste de Togo e no sudeste de Gana - como a origem do termo "jeje" 5 . Rodrigues também considera que a palavra "jeje" vem do termo "geng", ou "gen", que hoje em dia designa o dialeto do povo "mina" do Togo e do sudoeste do Benin (ver, p. ex., Rodrigues 1988[1905]:105-106, 232; Cacciatore 1977:153; Capo 1984:168). Evidentemente, Rodrigues não sabia que a pronúncia do " $g$ " inicial em "geng" e "gen" equivale ao "gue" em português, pouco se assemel hando ao " $j$ " fricativo na palavra "jeje". Nem sabia, evidentemente, que a língua jeje documentada no Brasil e na África manifesta laços muito mais fortes com o dialeto fon do que com o dialeto gen. Segurola, lexicógrafo da língua fon, nega que o termo "jeje" se origine de qualquer modo da língua fon (Segurola 1968[1963], vol. I:264). Elbein dos Santos (1993[1975]:31, nota 11) duvida que a origem da palavra "jeje" seja de algum modo conhecida, mas ela atribui aos administradores coloniais franceses a sua aplicação inicial aos vários grupos étnicos nos arredores de Porto-N ovo. Verger (1970[1957]: 19), por sua vez, afirma que "jeje" vem do termo "aja", o qual designa o povo do sudoeste do Benin e do Togo Oriental que deu à luz dinastias governantes de Allada, Porto-N ovo e A bomey6. J á Costa Lima oferece a interpretação alternativa de que "jeje" vem da palavra yorùbá para "estrangeiro" (àjèjì), em referência a esse grupo de povos vizinhos (Costa Lima 1977:14-15; A braham 1962[1946]:38), enquanto Suzanne Blier (1995) acha que vem do nome da aldeia Adjadji, perto de Allada. Alguns a identificam como uma das origens da dinastia aja-tado, que reinava nas cidades de Allada, Porto-N ovo e A bomey (Comunicação pessoal, 21 de outubro de 1997; Blier 1995:405, 408). Esta parece a mais provável dentre as múltiplas possibilidades.

A lém disso, tais explicações etimológicas não dão conta de como a palavra "jeje" chegou a ser adotada e utilizada pelo grupo internamente, especialmente em data tão recente. Este último fato sugere que o uso do termo "jeje" para designar todos esses falantes de ewe, gen, aja e fon se originou no Brasil, onde aparece na historiografia a partir de meados do século XVIII - 120 anos antes do seu surgimento na historiografia do Golfo da Guiné.

Não obstante, o registro do uso do termo na África depois de 1864 revela muito sobre a história da etnicidade e da nação, regional e transatlanticamente. Desde o segundo terço do século XIX, centenas e talvez milhares de jejes brasileiros regressaram ao Golfo da Guiné: a Lagos, Porto-N ovo, Ouidah, Grand-Popo, Petit-Popo, Agoué e Porto-Seguro (o último tendo sido fundado pelos retornados mesmos). Como comerciantes e donos de escravos eles próprios, alguns dos retornados reingressavam no 
Brasil, indo e vindo regularmente ao Golfo da Guiné, à Bahia e a Cuba. Foram evidentemente esses viajantes que aplicaram o nome "jeje" a todos os africanos que el es consideraram seus parentes, apesar de ser pouco provável que esses "parentes" assim se identificassem inicialmente.

Sabemos desses desenvolvimentos pelos escritos dos padres da Sociedade das M issões A fricanas - organização francesa que, como hóspede dos retornados afro-brasileiros prósperos, "missionarizaram" essa região no final do século XIX (ver Turner 1975). Os padres da Sociedade foram os primeiros europeus a designar ewe, gen, aja e fon como sendo todas a mesma língua, e os primeiros europeus a chamar essa língua e todos os seus falantes de "jeje" 7 . Seguindo essa designação, um agente comercial francês escreveu um dicionário e manual de instrução da língua "djedji" (D'A lbéca 1889), baseado no subdialeto do fon falado em Porto-N ovo, cidade onde os retornados brasileiros e a Sociedade das M issões Africanas tinham uma presença acentuada no final do século XIX. Assim, desde 1864 até 1889, os retornados brasileiros, a Sociedade das M issões A fricanas e os franceses, cujos interesses comerciais Ihes encorajaram a estudar a língua da cartilha de D'Albéca, institucionalizaram o nome "djedji" e fizeram de Porto-N ovo a capital do imperialismo cultural local.

Porém, al go mudou de fato. De 1902 em diante, os termos "djedji", "djedj" e "gège" foram aplicados específica e exclusivamente aos habitantes indígenas de Porto-N ovo ${ }^{8}$. Embora o termo não mais denotasse a totalidade dos falantes de ewe, gen, aja e fon, tornou-se central nos esforços coloniais franceses de preservar a sua soberania sobre a, na época, colônia de Daomé. Os administradores franceses temiam constantemente não só a conquista militar britânica dessa região, mas também sua conquista comercial e cultural. Os franceses impunham tarifas sobre as importações britânicas e puniam o uso da moeda britânica. Queixavamse que missionários protestantes yorùbá haviam fundado escolas onde os governados pelos franceses foram instruídos em inglês. M esmo a Sociedade das M issões Africanas, baseada na França, havia escolhido a língua yorùbá, em vez do francês ou do jeje, como a língua de instrução. Os missionários franceses fizeram isso porque os missionários yorùbás negros da Church M ission Society (Sociedade M issionária da Igreja) britânica já haviam estabelecido uma expressiva literatura nessa língua franca local ${ }^{9}$.

Para os administradores coloniais franceses, a língua, o poder militar e o comércio britânicos, tanto quanto a língua, a liderança religiosa e o comércio yorùbás eram ameaças inseparáveis à soberania francesa. Embora muitas gerações dos ancestrais dos nagô, ou yorùbá, tivessem nascido e morado em Porto-Novo, que era então a capital colonial, os 
franceses sempre os viram com maus olhos. Em contraste com os "djedji", os yorùbá eram chamados de "enganosos", "difíceis", "miséraveis" e "estrangeiros" 10 . A pesar de os Oyo e outros povos protoyorùbás terem sido, há muito tempo, uma forte e velha influência cultural, lingüística e política nessa região, os franceses esforçaram-se para naturalizar a distinção entre os "yorùbá" e o povo local sobre quem os franceses se sentiram capazes de reivindicar soberania sem ambigüidade. Em outros termos, a campanha francesa contra o imperialismo anglo-yorùbáno destacou a identidade étnica “djedji” na colônia de Daomé até, pelo menos, o início dos anos 30.

Porém, antes do fim dos anos 30 , esse rótulo étnico e a hegemonia dos porto-novianos e retornados brasileiros - aqueles que sustentaram esse rótulo - se extinguiram. Quanto à razão desse desaparecimento, minha hipótese é a de que a política francesa de assimilar, especialmente, as elites brasileiras privou-as do incentivo que, por exemplo, os yorùbás na Lagos racista tiveram para reafirmar a dignidade da sua nação africana. Nos anos 30, porém, os limites de assimilação ficaram evidentes para os africanos e caribenhos residentes em Paris. Algumas das suas respostas, como o movimento N égritude, receberam inspiração da Renascença do Harlem e também do movimento de M arcus Garvey no mundo anglofônico (ver, p. ex., Vaillant 1990; Langley 1973:286-325; Ballard 1965; Kaké 1982:204-205). Esses assimilés residentes em Paris geraram outro termo - fon - para nomear sua unidade e dignidade (ver, p. ex., Quénum 1938[1931]).

Resumindo, entre 1864 e 1889, o nome "djedji" e as suas contrapartes identificavam juntos todos os falantes de ewe, gen, aja e fon. Entre 1902 e a década de 30, identificavam apenas os habitantes de Porto-Novo; e, durante os anos 30, esses nomes se extinguiram progressivamente na região do Golfo da Guiné, cedendo seu lugar ao rótulo "fon". O rótulo e a identidade étnica "fon" não foi centrado no local onde os franceses entraram e estabeleceram a sua futura capital colonial - quer dizer, Porto-Novo - , mas sim no reino que mais resistiu à intrusão colonial francesa. O termo "fon" denotava especificamente a identidade étnica da dinastia real do reino de Daomé (Lombard 1967:72). Por isso, depois que os horrores do regime daomiano foram esquecidos, este reino virou um símbolo conveniente da independência africana. 


\section{O colonialismo francês e a nação transatlântica}

Não devemos nos esquecer, porém, que entre 1820 e a década de 30 , os jejes brasileiros não voltavam simplesmente para a África. Eles iam e vinham fazer comércio e peregrinação, e alguns dos mais ricos afro-brasileiros circulavam entre o Brasil, Cuba e o Golfo da Guiné. A presentavamse elegantes em seus paletós com relógios de bolso (ver, p. ex., M anuela Carneiro da Cunha 1985:130). A o menos um jeje brasileiro - J oaquim d'Almeida - possuiu escravos em três continentes (Verger 1976:475-476, nota 16). Houve também o rico comerciante jeje, J oaquim Francisco Devodê Branco, que viajou inúmeras vezes entre Lagos, Porto-N ovo e Salvador. Ao morrer, ele legou grande soma de dinheiro à família do seu exdono, uma família branca que caiu na miséria (Olinto 1980:188-190, 269; 1964:213-215, 267; Laotan 1943:16; Marianno Carneiro da Cunha 1985)11.

Segundo informações, no final do século XIX, a nação jeje na Bahia havia sofrido uma baixa tão grande que ela quase se extinguiu. Conforme Nina Rodrigues, nenhum canto ou irmandade jeje e pouquíssimos jejes (auto-identificados como tais) lá existiam naquela época (Rodrigues 1945[1905]:179-180). Contudo, algo aconteceu para ressuscitar essa nação, naquele estado, ainda antes dos anos 30 , quando numerosos terreiros jejes floresceram. A minha hipótese é que a posição de destaque simbólico dada à identidade étnica "djedji" pelos franceses no Daomé colonial no começo do século XX, desempenhou um papel importante na ressurreição e renovação da nação jeje baiana.

\section{Textos e contextos da nação transatlântica}

Observadores baianos que leram sobre a adoração de cobras no Golfo da Guiné se surpreenderam ao descobrir que essa forma religiosa estava ausente na Bahia do final do século XIX. Mas, de repente, literalmente, ela foi pintada nas paredes das casas jejes baianas a partir dos anos 30 (Carneiro 1948:50-51; 1986[1948]:9-12).

Entre fins do século XVIII e o final do século XIX, grande parte dos falantes do grupo dialetal ewe-gen-aja-fon na Bahia era "maxi" 12. A té hoje, a maioria dos terreiros da nação jeje autodeclara-se "marrim" (maxi) ou "savalu". Essa proeminência histórica dos Maxi na Bahia ajuda-nos a entender a raridade da cobra na religiosidade baiana no final do século XIX. Os M axi no Golfo da Guiné praticaram pouco a adoração do deus-serpente ${ }^{13}$. M as como se explica a ascensão do deus-cobra na 
Bahia no século $X X$ ? Considero que a comunicação no começo deste século entre a Bahia e o Golfo da Guiné implica o ressuscitamento da nação jeje e a adoção por parte da mesma do deus-serpente como seu emblema. Os famosos marrins baianos que regressaram à África e mantiveram contato com a Bahia normalmente, estabeleceram os seus quartéis-generais não na terra interior dos $\mathrm{M}$ axi, mas no litoral, onde a adoração do deus-serpente era central na religião dos nativos, tendo marcado a distinção dos jejes na sociedade euro-africana da costa.

A influência da sociedade posterior ao tráfico de escravos é explicitada pelo fato de a vasta maioria dos jejes importados no início como escravos vir de uma região conhecida pela ausência do deus-serpente. A adoração deste assumiu um destaque sem precedentes na Bahia durante o período de intenso comércio pós-escravocrático com o litoral ofiolátrico da África. A lém das viagens dos $M$ arrins baianos ao litoral africano, especula-se sobre a existência de um outro meio transoceânico de influência na religião jeje baiana no século XX: o jornalista e etnógrafo Edison Carneiro, de posse de uma cópia do Esboço da Crença Religiosa Daomeana, publicado por M elville e Frances Herskovits em 1933, provavelmente divulgou o conteúdo ou uma cópia deste para os seus amigos jejes. (Cabe mencionar que este livro foi pesquisado nas sub-regiões do Golfo da Guiné onde o deus-serpente era relativamente importante.)

Tal livro, assim como outros textos, inclusive a cartilha da Sociedade Missionária da Igreja - I we Kika Ekerin Li Ede Yoruba (A Quarta CartiIha na Língua Yoruba), de A. L. Hethersett -, e também o livro The Yoruba-Speaking Peoples of the Slave Coast of West Africa (Os Povos YorubaFalantes da Costa de Escravos da África Ocidental), publicado por A.B. Ellis em 1894, estavam disponíveis na Bahia, e mesmo em Cuba, nas primeiras décadas do século XX (ver Rodrigues 1988[1905]; Ortiz 1973 [1906]). Temos também evidências de que textos, como a cartilha anglicana em yorùbá, mencionada acima, foram não só traduzidos, mas criticados, pelos viajantes afro-brasileiros que serviram de informantes para uma geração de etnógrafos no Brasil (A ndrade Lima 1984:7). Tais escritos eram importantes fontes de informação que os chamados fundadores dos estudos afro-brasileiros e afro-cubanos tinham sobre a África supostamente "original". M as, muitos deles foram, de fato, redigidos, traduzidos e criticamente interpretados por africanos cosmopolitas e "crioulizados". A pesar de Os Povos Yoruba-Falantes... ter sido escrito pelo coronel Ellis do Regimento British West India em Lagos, ele o foi em meio ao vigoroso "nacionalismo cultural" de Lagos dos anos 1890, que é muitas vezes chamado de a "Renascença Cultural Yorùbá". 
Considero o trabalho de etnógrafo e de detetive de arquivos extremamente importante. Ele nos permite colocar em questão o padrão teórico de representação da cultura africana nas Américas, que fala de memória coletiva na ausência de agency, ou intencionalidade estratégica, dos diversos atores. Falando quer da "Santería" e Candomblé, quer de "shouting" (isto é, o dançar e falar sob a influência do Espírito Santo nas igrejas negras dos Estados Unidos), quer discutindo a identificação negra com a Etiópia bíblica ou o movimento de repatriação de M arcus Garvey, quer ol hando a ordem política dos quilombos, palenques e maroon societies, a África que vive nas A méricas negras não deve ser medida em termos da sobrevivência mais ou menos pura de um "alhures" primordial. A África que vive nas Américas é uma mobilização estratégica de um repertório cultural circum-Atlântico de quinhentos anos. Em suma, muito do que é chamado de "memória" cultural ou coletiva na diáspora africana, e em toda nação, ocorre em contextos de poder, negociação e recriação. Este ponto é geralmente negligenciado pelo discurso da “invenção da tradição", tornando nula a agency dos oprimidos.

\section{Nações e transnacionalismo}

O caso das nações afro-latinas compromete a lógica primordialista da história convencional dos grupos étnicos africanos, mas também fala da literatura recente sobre a nação e o transnacionalismo. Em primeiro lugar, o caso em tela demonstra que comunidades diaspóricas, poderosamente imaginadas, desenvolviam-se ao mesmo tempo que a nação territorial. $\mathrm{E}$ o fato de essas "nações" diaspóricas se fazerem representar por um vocabulário paralelo ao da nação territorial - isto é, ambas são chamadas de "nações" - aponta para um diálogo que é evidente de muitos outros modos. Lembrem-se que a idéia de nação territorial era, ela mesma, recém-nascida no século XIX. No Brasil, ela surgiu até mais tarde do que nas demais nações americanas, segundo a definição andersoniana de nação o Brasil ainda era um império real até 1889. De fato, uma das chaves do sucesso extraordinário dessas nações diaspóricas é que muitas pessoas negras e mulatas não achavam convincente, de jeito nenhum, a "imaginação" da sua cidadania na nação territorial. Consideravam-se, freqüentemente, excluídos dos direitos e privilégios dessa cidadania. Achavam mais impressionantes e convincentes as formas de inclusão, imaginário literário e pompa associados com as nações diaspóricas. A demais, essas pessoas negras e mulatas não estavam sozinhas nessa prefe- 
rência; muitos brancos também aderiram. $O$ ponto é que os mapas talvez convençam alguns de nós de que as identidades associadas às nações territoriais constituem a trajetória avassaladora e exclusiva desses dois séculos passados da história política. A proliferação recente de green cards (quer dizer, de vistos de residência para não-cidadãos nos Estados Unidos) talvez convença alguns de que as identidades transnacionais realmente começaram a existir apenas há trinta anos.

Ao contrário, o meu argumento é que essas nações afro-latinas configuram um caso paradigmático de um amplo fenômeno iniciado há muito, e que a própria nação crioula emergiu em diálogo com elas. Em uma série de nações americanas, as elites burguesas locais escrevem, pintam e dramatizam as imagens que elas associam à população subordinada de negros ou índios como prova da "autenticidade" dessas elites e do direito da mesma de governar. Outras vezes, essas imagens servem como metáfora da convivência harmoniosa entre facções da elite potencialmente em conflito (ver Sommer 1990:131-165). Sem concederem poder político algum a essas populações de cor, tais elites se auto-representam como os descendentes do "povo" (ver, p. ex., Hoetink 1973:131-165; Skidmore 1974:6-7; Anderson 1991[1983]:154; Helg 1990). Esses motivos inspiraram vários indianismos, indigenismos, a negritude, o afro-cubanismo, o negrigenismo de Fernando Ortiz, o movimento afro-crioulo, a celebração da mulatice, o "ciclo do negro" e outros movimentos semelhantes em toda parte das A méricas. Dificilmente existe uma nação territorial no Novo $M$ undo que não tenha se preocupado - como precondição para se tornar nação - com a representação, incorporação ou aniquilamento dessas comunidades da diáspora africana (Ortiz 1995[1947]; 1973[1906]; Helg 1990; A ndrews 1980; Freyre 1986[1933]; Herskovits 1958[1941]; PriceM ars 1983[1928]; A guirre Beltrán 1989). M esmo onde os índios importavam mais como símbolos do Outro interno, o africano estava freqüentemente presente também. De fato, mitos e literaturas indianistas fortes surgiram em lugares onde os índios foram efetivamente exterminados (como no Uruguai, na República Dominicana e nos Estados Unidos) e onde os brancos locais, por meio desse simbolismo indianista, resistiram à concessão de direitos de cidadania aos negros (como no Brasil, na República Dominicana e nos Estados Unidos do século XIX). A auto-imagem das nações territoriais americanas tem uma lógica às vezes transparentemente simples e às vezes complexa, mas sempre dialética, contrastando a superioridade das origens diaspóricas com a inferioridade dos indígenas governados ou, quando útil, contrastando a fraternidade indígena com a contaminação diaspórica. Assim, vale a pena comparar essa carac- 
terística das nações americanas com a relação das nações européias emergentes com o protótipo de todas as diásporas - a judaica - , a natureza cosmopolita da qual ameaçou e conformou dialeticamente a autoimagem da nação territorial européia.

Em meio à nossa autocongratulação no que se refere à redescoberta do transnacionalismo, é bastante fácil negligenciar o óbvio: que a maciça dispersão de populações africanas e européias precedeu em muito à fundação do Estado-nação no Novo Mundo. Pode ser menos óbvio para alguns que a duradoura identificação com a terra-mãe européia tem sido igualmente importante na história do Novo M undo, como tem sido a celebração do conceito de cidadania homogênea dentro dos limites do território nacional ${ }^{14}$. Por um lado, a imagem de fraternidade igualitária - a qual muitos antes de mim chamaram "indigenismo" - é associada com apelos à solidariedade contra os inimigos estrangeiros, usualmente colonizadores europeus continentais (ver, p. ex., Hoetink 1973:131-165; Anderson 1991[1983]:154). Por outro lado, a imagem de origens longínquas - à qual eu chamo diasporismo - é associada com apelos a uma hierarquia dentro da nação. Em outros termos, “é exatamente porque somos originários de um lugar que é outro e superior", assim vai o raciocínio, "que temos o direito de governar aqui". Embora a idéia de fraternidade indígena e compartilhada tivesse grande importância nesses Estados-nação, também importa a imagem de origens raciais diaspóricas. Atente-se para o fato de que esses sentimentos de superioridade diaspórica são também padrão nas nações afro-latinas. De fato, o autoconceito de superioridade e pureza nagô e jeje foi exatamente o que atraiu as elites brancas do Brasil nordestino - para não mencionar a comunidade cubana em exílio nos Estados Unidos - às nações afro-latinas.

\section{Conclusão}

No passado, antropólogos, historiadores e outros estudiosos da cultura negra tenderam a supor que os cativos africanos nas Américas se originaram de grupos étnicos africanos cujas culturas preexistentes "sobreviveram" na diáspora até elas desaparecerem aos poucos pelo processo de assimilação. Ao contrário, tenho argumentado que al guns dos grupos africanos e afro-americanos mais importantes são transatlânticos na sua gênese. Embora supostamente primordiais, certos grupos étnicos na Á frica não teriam existido senão pelos esforços dos regressados da diáspora. O grupo étnico jeje é um desses casos que estende a duração do fenôme- 
no cultural e politicamente transformador, que é atualmente chamado de "transnacionalismo". Não menos importante, esse caso demonstra que tais unidades sociopolíticas não prefiguram a morte do Estado-nação, ao contrário, acompanharam a sua subida e continuam constituindo-o dialeticamente.

Parece-me que as nações americanas emergentes nos últimos dois séculos (e, de certo modo, todas as nações) se caracterizam menos pela constante imaginação de uma comunidade fraternal e territorialmente limitada de cidadãos iguais, do que pela alternância estratégica entre discursos de indigenismo e diasporismo - cada um acarretando as suas próprias construções coletivas de comunidade por meio de memória, ritual e texto. Nesse sentido, este ensaio não pretende simplesmente demonstrar a agency dos afro-americanos no diálogo que, simultaneamente, conformou a nação territorial americana e uma gama de suas alternativas poderosas, mas sobretudo ilustrar os discursos ideológicos contrários - o indigenista e o diaspórico - que têm conformado a própria nação territorial desde o seu começo.

Desse ponto de vista, é difícil endossar o consenso crescente de que o transnacionalismo prognostica a morte do Estado-nação. Parece-me que os discursos e a realidade de dispersão e do comércio internacional têm sido, há muito, a fonte vital e um princípio lógico que constitui o Estado-nação americano. Há numerosos exemplos de nações territoriais que exploram e se aproveitam dos impostos de populações imigrantes e itinerantes. Todas as nações territoriais negociam com o capital internacional. Todas negociam com nações e impérios militarmente mais poderosos. Elas invocam signos culturais e lingüísticos de sua identificação com uma ou outra "grande" nação. M esmo no auge da sua soberania e integridade territorial, nenhuma nação escapou a tais interações transnacionais. De fato, a nação territorial é constituída por elas.

Recebido em 6 de setembro de 1997

Reapresentado em 24 de julho de 1998

A provado em 29 de agosto de 1998 
J . Lorand M atory é professor de Antropologia e de Estudos Afro-Americanos na Harvard University. É autor de numerosos artigos sobre as religiões e as sociedades da África Ocidental e a diáspora africana nas Américas. Seu livro Sex and the Empire that Is No M ore (University of Minnesota, 1994) trata do papel das mulheres e dos homens travestis na religião e na política do reino de Oyo, na Nigéria. Seu próximo livro - The Trans-A tlantic N ation: Tradition, Transnationalism and Matriarchy in the Rise of the Afro-Brazilian Candomblé - será publicado pela Princeton University Press.

\section{Notas}

1 Escrito em 1900 por J ames Weldon J ohnson e seu irmão J . Rosamond J ohnson, Lift Every Voice and Sing é conhecido pela maioria dos negros norteamericanos e é popularmente descrito como o "Negro National Anthem".

2 Ver J ohnson (1921[1897]:15), p. ex., entre os que descrevem esse grupo africano como uma "nação".

3 São as seguintes as fontes historiográficas e etnográficas que consultei em busca de menções ao rótulo étnico "djedji" e suas variantes. Os textos nos quais o termo aparece são marcados com asteriscos: Ogilby (1670); Barbot (1992[1688]); Des M archais (1703-1706); Bosman (1967[1704]); Labat (1731); Snelgrave (1734); Atkins (1970[1735]); Smith (1967[1744]); H ardwicke e Tweeddale (1745-1746); Smith (1751); Norris (1789); Dalzel (1967[1793]); Pires (1957[1800]); McLeod (1820); Duncan (1968[1847]); Forbes (1851); Burton (1966[1861-64]); Borghero (1864:423)*; Bouche (1868)*; Bourquet (1872:2, 4)*; Bourquet (1873)*; Desribes $(1877: 309,318,322) *$; Wood (1881); Baudin (1885); Bouche (1885:20, 77, 107)*; D'Albéca (1889)*; Ellis (1970[1890]); Akinsowon (1930[1914]), Labouret e Rivet (1929, que inclui uma cópia da Doctrina Christiana, y Explicación de sus M isterios, en Nuestro Idioma Español, y en Lengua Arda [1658]); Kiti (1929); Quénum (1938[1931]); Herskovits e Herskovits (1976[1933]); “Coutumes Nago et Djèdj...1933" (1939), Maupoil (1988[1934-36]), Renaud e Akindélé (1939); Herskovits e Herskovits (1967[1938]), Akindélé e Aguessy (1953); M ercier (1954); Verger (1966); Polanyi (1966); A kinjogbin (1967); e Manning (1982). Destaque-se que o dicionário de A ntonio da Costa Peixoto (1943-44[1741]), baseado na língua de escravos "mina" de M inas Gerais, em meados do século XVIII, não menciona a palavra "jeje" ou suas variantes. Ver, também, Moreau de Saint-M éry (1958 [1797]), o observador de Saint Domingue no final do século XVIII, cujo catálogo de grupos étnicos africanos na ilha não inclui menção do nome "djedji" ou suas variantes. O leitor notará adiante várias fontes africanistas do começo do século $X X$ que invocam sim o termo "djedji", embora em um sentido muito mais estrito que nas fontes mencionadas acima. 
4 A cartilha de Peixoto, conforme mencionado, baseou-se na fala de escravos "mina", que representa uma língua muito semelhante à língua moderna chamada "fon" (ver Rassinoux 1987).

5 É pouco provável que "ewe" seja a origem etimológica de "jeje"; a ewe pertence ao mesmo grupo dialetal ao qual pertence a língua chamada "jeje" na África Ocidental no século XVIII e no começo do século XX (Capo 1984; Eades 1980; Mercier 1954:210).

6 Ver, também, Rapport M onographique sur le Cercle de Porto-N ovo, pelo Administrateur en chef, 17 de abril de 1921, 1G353, bobine 200Ml/696, C.A.R.A.N., Archives Nationales de France, Paris.

7 “M ission du Dahomey ... . adressée par M. I'abbé Borghero, à M. I'abbé Planque... Whydah, 3 décembre 1863", Annales de la Propagation de la Foi, Tomo 36, 1864, p. 423; Bourquet a Planque, Entrada oo 17.047, Rótulo o 12/80200, Lagos, 26 de junho de 1872, pp. 2 e 4, arquivo da S.M.A., Roma; Carta de Bouche em Porto-N ovo a Superior, 1 o de fevereiro de 1868, 20.358, 12/80200, arquivo da S.M.A., Roma; Cópia de uma carta redatilografada de Bourquet em Lagos a Planque, 26 de junho de 1873, entrada no 17.047, Rótulo oo 12/80200, arquivo da S.M .A., Roma; Bouche (1885:20, 77, 107); Desribes (1877:309, 318, 322); também D'Albéca (1889).

8 Rapport Monographique sur le Cercle de Porto-N ovo, 1921, Archives Nationales de France, C.A.R.A.N., Paris (doravante A.N.F.P.), 1G353, bobine 200M I/696; "La Region de Porto-Novo", Revue du Dahomey et Dependances: Organe du Comite du Dahomey, ano III, nos 5-6, maio/junho de 1902, pp.1-2 (Bibliothèque Nationale de France, Paris [doravante, B.N.F.P.]); “Un enlevement sensationnel", Supreme Sagesse, ano V, no 7, 1o de julho de 1938, pp. 1-3, 7 (Bibliothèque Nationale de France, Versailles [doravante B.N.F.V.], Gr.fol-J 0-393, I, no 8V, no 9). “Coutumes Nago et Djèdj (Cercle de Porto-Novo), 1933”, Coutumiers J uridiques de I'A frique Occidentale Française, Tome III, Série A, no 10, pp. 475-530, Paris, Librairie Larose, 1939. Similarmente, o historiador brasileiro Braz do Amaral usa o termo "jeje" para descrever apenas os povos do litoral, excluindo, por exemplo, a população central do reino de Daomé, que fica no interior (A maral s/d:661-693 apud A rthur Ramos 1946:300-301n). Ver, também, Elysée Soumonni, carta para o autor, 6 de março de 1996; Costa Lima (1977:14-15); Rodrigues (1945[1905]:176); Verneau (1890-91:251).

9 Carta de Courdioux em Porto-Novo ao Superior Geral, 29 de abril de 1868 (20.374, 12/80200); carta de Bouche em Porto-N ovo a Planque, 1o de junho de 1868 (20.381, 12/80200); carta de Chausse em Porto-Novo ao Superior, 23 de outubro de 1872; carta de Bourquet em Lagos a Planque, 26 de junho de 1872 (17047, 12/80200); carta de Cloud ao Superior, 11 de outubro de 1872 (17057, 14/80200, 1872) - todas no arquivo da Sociedade das M issões Africanas, Roma.

10 "La Région de Porto-Novo", Revue du Dahomey et Dépendances: Organe du Comité du Dahomey, Paris, ano III, nos 5-6, maio/junho de 1902, pp. 1-2, 
B.N.F.P. Ver, também, Rapport M onographique sur le Cercle de Porto-N ovo. 1G353, bobine 200M I/696, Archives Nationales de France, C.A.R.A.N., Paris.

11 Ver o caso de outro viajante jeje, J oão J osé de M edeiros, em Le Phare du Dahomey, 15 de março de 1931, p. 9, B.N.F.V. Nascido em Ouidah, ele estudou no "Liceu da Bahia" antes de voltar para visitar a colônia de Daomé. Somente a morte de seu pai o impediu de continuar os estudos na Bahia.

12 Os arquivos no Estado da Bahia indicam que, em 1779, todos os poucos jeje cuja terra, ou sub-região de origem, foi mencionada eram identificados como "maxi" ou "savalu", esta última sendo historicamente a cidade mais poderosa de língua maxi (Verger 1976:599). O inventário de línguas faladas em Freetown, Serra Leoa, na década de 1840 - que provavelmente reflete a proporção entre os grupos lingüísticos da África Ocidental transportados às A méricas na primeira metade do século XIX - , sugere que o povo maxi era muito mais numeroso no tráfico do que os povos que indicaram as suas origens entre os povos vizinhos "fon", "hwida [ouidah]" e "adja". Em Freetown ao final da década, tinham "poucos" “Adja”, seis "Hwida", nenhum “Dahome" ou "Popo" e 30 "M ahi” (ver Curtin 1969:292). A o final do século, os maxi eram um grupo grande e expressivo entre os jejes da Bahia (Rodrigues 1988[1905]:106).

13 Bosman (1967[1704]:369 e ss.); Labat (1731:54-55, 133, 149, 154); Atkins (1970 [1735]:113); Hardwicke e Tweeddale (a assim-chamada "Astley Collection") (1745-1746:28); Dalzel (1967[1793], Tomo II:54); M cLeod (1820:32); Burton (1966 [1861-64]:73-77 e ss., 100); Desribes (1877:177-179); Bouche (1885:44-48); também Rodrigues (1945[1905]:367-368); Herskovits (1976[1933]:58); Quénum (1938 [1931]:72); A kindélé e A guessy (1953:68). Le Herissé talvez seja o único escritor que observa, embora sem muita ênfase, que os maxi também adoram a cobra ou arco-íris - "Dan-Aido-Ouêdo". Ele fez suas pesquisas principal mente em A bomey, e sua informação pode referir-se aos migrantes maxi do sul da colônia ou representar um desenvolvimento recente e marginal (1911:1-2, 118-119).

14 Ver, também, Wafer e Santana (1990), que argumentam que a história cultural do Brasil é dominada pela competição entre dois movimentos inteletuais euro-brasileiros: (1) o "movimento centrífugo" reconhece a presença no Brasil de múltiplas culturas exógenas, enquanto (2) o "movimento centrípeto" enfatiza que todos os brasileiros são mestiços do ponto de vista racial ou cultural, fazendo parte de um amálgama nacional. Em seu texto, os autores apresentam os afro-brasileiros que abraçam identidades africanas e proclamam a pureza ou superioridade de tais identidades como caricaturas ingênuas dos inteletuais euro-brasileiros e inimigos dos seus próprios interesses. 


\section{Referências bibliográficas}

ABRAHAM, R. C. 1962 [1946]. Dictionary of M odern Yoruba. London: Hodder and Stoughton.

AGUIRRE BELTRÁN, Gonzalo. 1989 [1946]. La Población Negra de México: Estudio Etnohistórico. Cidade do M éxico: Fondo de Cultura Económica.

AKINDÉLÉ, A. e AGUESSY, C. 1953. “Contribution a l'Étude de l'Histoire de I'Ancien Royaume de Porto-Novo". Mémoires de I'Institut Français d'A frique Noire, XXV. Dakar: I.F.A.N.

AKINJ OGBIN, I.A. 1967. Dahomey and its Neighbours 1708-1818. Cambridge: Cambridge University.

AKINSOWON, Aki[n]dele (a.k.a. Benjamin Coker). 1930 [1914]. I we Itan Ajas.e. ati Oniruru Asaro On Ila Aro (2th ed.). Lagos: Ife-Olu Printing Works.

AM ARAL, Braz do. s/d. As Tribos Negras Importadas. Rio de J aneiro: J . Leite.

ANDERSON, Benedict. 1991 [1983]. Imagined Communities: Reflections on the Origin and Spread of Nationalism. London/N ew York: Verso.

ANDRADE LIMA, Lamartine de. 1984. "Roteiro de Nina Rodrigues". Ensaios/Pesquisas II do Centro de Estudos Afro-Orientais. Universidade Federal da Bahia.

APPADURAI, Arjun. 1990. “Disjuncture and Difference in the Global Cultural Economy". Public Culture, II(2):124.

. 1996. M odernity at Large: Cultural Dimensions of G lobalization. Minneapolis: University of Minnesota Press.

ATKINS, J ohn. 1970 [1735]. A Voyage to Guinea, Brazil, and the West Indies. London: Frank Cass.
BALLARD, J . A. 1965. “Les Incidents de 1923 à Porto-N ovo: La Politique à l'Époque Coloniale". Études Dahoméenes (N.S.), 5:69-87.

BARBOT, J ean. 1992 [1688]. Barbot on Guinea: The Writings of J ean Barbot on West Africa 1678-1712 (edited by P.E.H. Hair, Adam J ones e Robin Law). London: Hakluyt Society. 2 vols.

BASTIDE, Roger. 1978 [1960]. The African Religions of Brazil. Baltimore: The J ohns Hopkins University Press.

BAUDIN, Noel. 1885. Fetichism and Fetich Worshipers. New York: Benziger Bros.

BORGHERO, Francesco. 1864. “Missions du Dahomey ... Adressée par $M$. I'A bbé Borghero, à $M$. I'A bbé Augustin Planque, Supérieur des $M$ issions Africaines à Lyon". Annales de la Propagation de la Foi, XXXVI:419-444.

BOSMAN, William. 1967 [1704]. A New and Accurate Description of the Coast of Guinea. London: Frank Cass.

BOUCHE, Pierre. 1885. Sept Ans en Afrique Occidentale: La Côte des Esclaves et le Dahomey. Paris: Librairie Plon.

BRANDON, George. 1993. Santeria from Africa to the New World: The Dead Sell Memories. Bloomington: Indiana University Press.

BURTON, Richard. 1966 [1861-64]. A Mission to Gelele, King of Dahomey. London: Routledge and Kegan Paul. CABRERA, Lydia. 1983 [1954]. El Monte. Miami: Colleción del Chicherekú.

CACCIATORE, Olga Gudolle. 1977. Dicionário de Cultos A fro-Brasileiros. 
Rio de J aneiro: Forense Universitário.

CAPO, Hounkpati. 1984. "Elements of Ewe-Gen-Aja-Fon Dialectology". In: F. de Medeiros (org.), Peuples du Golfe du Bénin (Aja-Ewé). Paris: Karthala/Centre de Recherches Africaines. pp. 167-178.

CARNEIRO, Edison. 1948. Candomblés da Bahia. Salvador: Museu do Estado/Secretaria de Educação.

CARNEIRO DA CUNHA, Manuela. 1985. Negros, Estrangeiros. São Paulo: Brasiliense.

CARNEIRO DA CUNHA, Marianno. 1985. Da Senzala ao Sobrado: Arquitetura na Nigéria e na República Popular do Benim. São Paulo: N obel.

CLIFFORD, J ames. 1997. Routes: Travel and Translation in the Late 20th Century. Cambridge: Harvard University Press.

COSTA LIMA, Vivaldo da. 1976. “O Conceito de 'N ação' nos Candomblés da Bahia". Afro-Asia, 12:65-90.

.1977. A Família-de-Santo nos Candomblés J eje-Nagôs da Bahia: Um Estudo de Relações Intra-Grupais. Tese de Mestrado, Universidade Federal da Bahia.

“Coutumes Nago et Djèdj (Cercle de Porto-Novo), 1933". 1939. Relatório A nônimo. In: Coutumiers J uridiques de l'A frique Occidentale Française, III, Série A, no 10, pp. 474-530.

CURTIN, Philip D. 1969. The Atlantic Slave Trade: A Census. Madison/ London: University of Wisconsin Press.

D'ALBÉCA, Alexandre L. 1889. Les Établissements Français du Golfe de Bénin: Géographie, Commerce, Langues. Paris: Librairie Militaire de I. Baudoin et Cie.

DALZEL, Archibald. 1967 [1793]. The History of Dahomey: An Inland Kingdom of A frica. London: Frank Cass.
DES MARCHAIS, Chevalier Étienne Renaud. 1703-1706. I ovrnal de Navigation de la Coste de Gvinnée Isles de LA merique et Indes DEspagne Svr Le Vaisseav Dv Roy Le Favcon François Armé Par Lordre De Sa Maisté Povr La Royalle Compagnie De LAssiente. Imprint.

DESRIBES, E. 1877. L'Évangile au Dahomey et à la Côte des Esclaves, ou, Histoire des $M$ issions Africaines de Lyon. Clermont-Ferrand: Imprimerie Centrale, Meneboode.

DUNCAN, J ohn. 1968 [1847]. Travels in Western Africa in 1845 and 1846. London: Frank Cass.

EADES, J. S. 1980. The Yoruba Today. Cambridge: Cambridge University Press.

ELBEIN DOS SANTOS, Juana. 1993 [1975]. Os Nagô e a M orte. Petrópolis, RJ : Vozes.

ELLIS, A. B. 1970 [1890]. The Ewe-Speaking Peoples of the Slave Coast of West A frica. Oosterhout, Netherlands: Anthropological Publications. . 1964 [1894]. The Yoruba-Speaking Peoples of the Slave Coast of West Africa. Chicago: Benin Press.

Encontro de Nações-de-Candomblé. 1984. A presentações do Encontro de Nações-de-Candomblé, Centro de Estudos Afro-Orientais, Salvador, 1 o a 5 de junho de 1981. Salvador: Ianamá, Centro de Estudos Afro-Orientais da Universidade Federal da Bahia, Centro Editorial e Didático da UFBA. Série “Estudos/ Documentos", oo 10.

FORBES, Frederick E. 1851. Dahomey and Dahomans, Being the J ournals of Two Missions to the King of Dahomey, and Residence at His Capital, in the Years 1849 and 1850. London: Longman, Brown, Green e Longmans.

FREYRE, Gilberto. 1986 [1933]. The 
Masters and the Slaves (Casa-Grande e Senzala). Berkeley: University of California Press.

GLICK SCHILLER, N., BASCH, L. e BLANC-SZANTON, C. (orgs.). 1992. Towards a Transnational Perspective on Migration: Race, Class, Ethnicity, and Nationalism Reconsidered. New York: New York Academy of Science. HANNERZ, UIf. 1996. Transnational Connections. London: Routledge.

HARDWICKE, C. Grafton e TWEEDDALE, Argyll. 1745-1746. A New General Collection of Voyages and Travels: Consisting of the Most Esteemed Relations, which have been hitherto published in any Language: Comprehending every Thing remarkable in its Kind, in Europe, Asia, Africa, and America. Vols. II and III. London: Thomas Astley.

HELG, Aline. 1990. “Race in Argentina and Cuba, 1880-1930: Theory, Policies, and Popular Reaction". In: R. Graham (org.), The Idea of Race in Latin America, 1870-1940. Austin: University of Texas Press. pp. 35-69.

HERSKOVITS, Melville J. e HERSKOVITS, Frances S. 1967 [1938]. Dahomey. Evanston: Northwestern University Press. 2 tomos. .1976 [1933]. An Outline of Dahomean Religious Belief. Millwood: Kraus Reprint (publicado originalmente em M emoires of the A merican Anthropological Association, $X X X X I)$.

HETHERSETT, A. L. 1944 [1912?]. I we Kika Ekerin Li Ede Yoruba. Lagos/ Exeter: C.M.S. Bookshop/J ames Townsend and Sons.

HOBSBAWM, Eric e RANGER, Terence (eds.). 1992 [1983]. The Invention of Tradition. New York/Oakleigh, Australia: Cambridge University Press/ Canto.

HOLLOWAY, J oseph E. 1990. “The Ori- gins of African-American Culture". In: J. E. Holloway (org.), Africanisms in American Culture. Bloomington: Indiana University Press. pp.1-18.

J OHNSON, Rev. Samuel. 1921 [1897]. The History of the Yorubas: From the Earliest Times to the British Protectorate. Lagos: C.S.S. Bookshops. KAKÉ, Ibrahima B. 1982. “The Impact of A fro-Americans on French-Speaking Black Africans, 1919-1945". In: J. E. Harris (org.), Global Dimensions of the African Diaspora. Washington, D.C.: Howard University Press. pp. 195-209.

KITI, Gabriel. 1929. “Rites Funéraires Usités Chez les Alladanous et Diverse Tribus de Race Goun ou Aïzo Habitant la Banlieue de Porto-N ovo". Les M issions Catholiques 3.097 (1 nov.). Lyon: Bureaux de la Propagation de la Foi.

KUBIK, Gerhard. 1979. Angolan Traits in Black M usic, Games and Dances of Brazil: As Study of African Cultural Estensions Overseas. Lisboa: J unta de Investigações Científicas do UItramar/Centro de Estudos de Antropologia Cultural.

LABAT, K. 1731. Voyage du Chevalier des Marchais en Guinée, I sles Voisines, et a Cayenne, Fait en 1725 , 1726 and 1727 , enrichi d'un grand nombre de Cartes et de figures en Tailles douces (tomo II). Amsterdam: Aux Dépens de la Compagnie.

LABOURET, Henri e RIVET, Paul. 1929. Le Royaume d'Arda et son Évangélisation au XVIIe Siècle. Paris: Institut d'Ethnologie.

LANGLEY, J. Ayodele. 1973. Pan-Africanism and Nationalism in West Africa, 1900-1945. Oxford: Clarendon.

LAOTAN, A. B. 1943. The Torch Bearers, or Old Brazilian Colony in Lagos. Lagos: Ife-Olu Printing Works. 
LE HERISSÉ, A. 1911. L'A ncien Royaume du Dahomey: Moeurs, Réligion, Histoire. Paris: Émile Larose, LibraireÉditeur.

LOMBARD, Patrick. 1967. "The Kingdom of Dahomey". In: D. Forde e P. M. Kaberry (eds.), West African Kingdoms in the Nineteenth Century. London: Oxford University Press. pp. 70-92.

MANNING, Patrick. 1982. Slavery, Colonialism and Economic Growth in Dahomey, 1640-1960. Cambridge: Cambridge University Press.

MATORY, J . Lorand. no prelo. The TransAtlantic Nation: Tradition, Transnationalism and $M$ atriarchy in the Rise of the Afro-Brazilian Candomblé. Princeton: Princeton University Press.

MATTOSO, Katia M. de Queiros. 1986 [1979]. To Be a Slave in Brazil, 15501888 (tradução de Arthur Goldhammer). London: Rutgers University Press.

MAUPOIL, Bernard. 1988 [1934-36]. La Géomancie à l'Ancienne Côte des Esclaves. Paris: Institut d'Ethnologie.

MCLEOD, John. 1820. A Voyage to Africa with Some Account of the Manners and Customs of the Dahomian People. London: J ohn M urray.

MERCIER, P. 1954. "The Fon of Dahomey". In: D. Forde (org.), African Worlds. Plymouth: International African Institute/Oxford University Press. pp. 210-234.

MÉTRAUX, Alfred. 1972 [1959]. Vodoo in Haiti (tradução de Hugo Charteris). N ew York: Schoken Books.

MOREAU DE SAINT-MÉRY. 1958 [1797]. Description Topographique, Physique, Civile, Politique et Historique de la Partie Française de I'I sle SaintDomingue. Paris: Société de I'Histoire des Colonies Françaises et $\mathrm{Li}$ brairie Larose.
NORRIS, Robert. 1789. Memoires of the Reign of Bossa Ahadee, King of Dahomey. London: W. Lowndes.

OGILBY, J ohn. 1670. Africa: Being an Accurate Description of the Regions of Aegypt, Barbary, Lybia, and Billedulgerid, the Land of the $\mathrm{Ne}$ groes, Guinee, Aethiopia, and the A byssines ... Collected and Translated from the M ost Authentick Authors, and augmented by later observations. London: Thomas J ohnson.

OLINTO, Antonio. 1980 [1964]. Brasileiros na África (2a ed.). São Paulo: G.R. Dorea.

. 1964. Brasileiros na África. Rio de J aneiro: Edições G.R.D.

ORTIZ, Fernando. 1973 [1906]. Los Negros Brujos. Miami: Ediciones Universal.

1995 [1947]. Cuban Counterpoint: Tobacco and Sugar. Durham/London: Duke University Press.

PEIXOTO, Antonio da Costa. 1943-44 [1741]. Obra Nova de Língua Geral de Mina. Manuscrito da Biblioteca Pública de Évora. Lisboa: Agência Geral das Colónias.

PIRES, Vicente Ferreira. 1957 [1800]. Viagem de Africa em o Reino de Dahomé. São Paulo: Editora Nacional.

PLIYA, J ean. 1970. Histoire Dahomey: Afrique Occidentale. Issy les M oulineaux: Classiques A fricains.

POLANYI, Karl. 1966. Dahomey and the Slave Trade. Seattle: University of Washington Press.

PRICE-MARS, Jean. 1983 [1928]. So Spoke the Uncle (Ainsi parla l'Oncle) (tradução de Magdaline W. Shannon). Washington, D.C.: Three Continents Press.

QUÉNUM, Maximilien. 1938 [1931]. Au Pays des Fons (Uses et Coutumes du Dahomey). Paris: Larose.

RAM OS, Arthur. 1946 [1937]. As Culturas Negras no Novo Mundo (2a 
ed.). São Paulo: Companhia Editora Nacional.

REIS, J oão J osé. 1987. Rebelião Escrava no Brasil: A História do Levante dos Malês, 1835. São Paulo: Editora Brasiliense.

. 1983. “Magia J eje na Bahia: A Invasão do Calundu do Pasto de Cachoeira, 1785". Revista Brasileira de História, VIII(16):57-81.

RENAUD e Akindélé. 1939. “La Collectivité chez les Goun de l'Ancien Royaume de Porto-Novo, 1938". Coutumiers J uridiques de l'A frique Occidentale Française III, Série A, № 10, pp. 535 e ss.

RODRIGUES, Raymundo Nina. 1945 [1905]. Os Africanos no Brasil. São Paulo: Companhia Editora Nacional.

1988 [1905]. Os Africanos no Brasi (7a ed.). Brasília: Editora Universidade de Brasília.

RUSSELL-WOOD, A. J . R. 1974. “Black and Mulatto Brotherhoods in Colonial Brazil: A Study in Collective Behavior". Hispanic American Historical Review, LIV (4):567-602.

SEGUROLA, R. P. B. 1968 [1963]. Dictionnaire Fon-Française. Porto-Novo, Benin (Dahomey): Centre Catéchétique de Porto-Novo. 2 tomos.

SMITH, Guillaume. 1751. Nouveau Voyage de Guinée. Paris: Chez Durand et Pissot. 2 tomos.

SMITH, William. 1967 [1744]. A New Voyage to Guinea. London: Frank Cass.

SNELGRAVE, William. 1734. A New Account of Some Parts of Guinea and the Slave Trade. London: J ames, J ohn and Paul Knapton.

SOMMER, Doris. 1990. “Irresistible Romance: The Foundational Fictions of Latin America". In: H. K. Bhabha (ed.), Nation and Narration. London: Routledge. pp. 71-98.
TURNER, J erry Michael. 1975. Les Brésiliens: The Impact of Former Brazilian Slaves upon Dahomey. Ph.D. Thesis, Boston University. Ann Arbor: University Microfilms.

VAILLANT, J anet G. 1990. Black, French, and A frican: A Life of Léopold Sédar Senghor. Cambridge: Harvard University Press.

VERGER, Pierre. 1966. “Le Fort St. J eanBaptiste D'Ajuda". Mémoire de I'Institut de Recherches Appliquées du Dahomey, I.

. 1970 [1957]. Notes sur le Culte des Orisa et Vodun à Bahia, la Baie de Tous les Saints, au Brésil et à l'ancienne Côte des Esclaves en Afrique (Re-impresso de Mémoires de l'Institut Français d'A frique Noire LI). A msterdam: Swets and Zeitlinger N.V.

. 1976. Trade Relations between the Bight of Benin and Bahia from the 17th to the 19th Century. Ibàdàn: Ibadan University Press.

. 1987. Fluxo e Refluxo do Tráfico de Escravos entre o Golfo do Benin e a Bahia de Todos os Santos dos Séculos XVII a XIX. São Paulo: Corrupio.

VERNEAU, René. 1890-91. Les Races Humaines. Paris: Librairie J .-B. Ballière et Fils.

WOOD, J. Buckley. 1881. “On the Inhabitants of Lagos: Their Character, Pursuits, and Languages". Church $M$ issionary Intelligence and Record (N.S), VI:683-691.

WOOD, Peter H. 1975. “'It Was a N egro Taught Them', a New Look at A frican Labor in Early South Carolina". In: R. D. Abrahams e J. F. Szwed (eds.), Discovering AfroAmerica. Leiden: E. J . Brill. pp. 2745. 


\section{Resumo}

Teóricos e observadores do transnacionalismo, ou globalização, tendem a perceber o fenômeno como sendo novo e antagônico à nação territorial. Este ensaio pretende demonstrar a célebre, porém pouco compreendida, natureza transnacional e histórica de uma "nação" africana no Brasil. Busca mostrar também que as identidades negras transnacionais evoluíram em um diálogo mutuamente transformativo com a nação territorial. Portanto, longe de prognosticar a morte desta última, este e outros fenômenos transnacionais têm sido essenciais na construção da nação territorial americana.

\section{Abstract}

Theorists and observers of transnationalism, or globalization, tend to regard the phenomenon as new and as antagonistic to the territorial nation. This essay seeks to establish the historical and transnational nature of one famous but little-understood African "nation" in Brazil and to show that such transnational black identities have evolved in a mutually transformative dialogue with the territorial nation. Therefore, far from prefiguring the demise of the territorial nation, these and other such transnational phenomena have been critical to the very construction of the American territorial nation. 